\title{
The Swiss Biotech Association (SBA) and Unitectra, the Joint Tech Transfer Organization of the Universities of Basel, Bern and Zurich - Two Organizations Initiated and Fostered by Oreste Ghisalba
}

\author{
Herbert Reutimann*
}

\begin{abstract}
Giving a voice to the small- and medium-sized biotech enterprises (SME) and putting Swiss biotechnology on the World map were important goals of Oreste Ghisalba when conceiving the Swiss Biotech Association (SBA). The SBA foundation was supported by the technology transfer office (TTO) Unitectra, which Ghisalba also initiated and which was instrumental in his endeavors to foster the collaboration between Swiss universities and the private sector. Laying the foundations for both the SBA and for Unitectra are major achievements of this visionary thinker.
\end{abstract}

Keywords: Innovation · Licensing · Spin-off company · Swiss biotechnology $\cdot$ Technology transfer

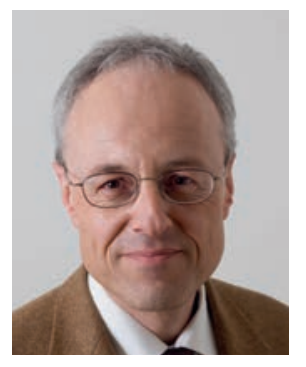

Dr. Herbert Reutimann supports startups and SME life sciences companies in the areas of licensing and IP management. $\mathrm{He}$ is a co-founder of Unitectra, in which he served as CEO from the foundation in 1996 until his retirement in fall 2019. He studied organic chemistry and got his $\mathrm{PhD}$ in protein chemistry from the ETH Zurich. Prior to starting in technology transfer and after several years of research at Karolinska Institute in Stockholm, Sweden, he worked in various fields and functions for different biotech and pharmaceutical companies, such as Roche, Sandoz and Pharmacia.

"The biotechnological wasteland" was a newspaper headline in 1995 claiming that Switzerland hardly hosted any biotech companies and that it wouldn't play a role in biotechnology on the international stage. While at that time there were a few venture capital (VC) -backed biotech start-up companies that were developing drugs, the importance of biotechnology in Switzerland was already much more significant than implied by this statement. The absence of a reliable overview of the biotech sector together with misleading media coverage prompted Ghisalba, Director of the Swiss Priority Programme Biotechnology of the Swiss National Science Foundation (SPP BioTech, 1992-2001), to initiate an inventory of companies with major activities in biotechnology.

Simultaneously, Ghisalba also established a technology transfer office for SPP Biotech, which was mandated to support the commercialization of research results and the negotiation of researchers' contracts (those participating in the program) for collaborative research projects with companies. Unitectra (named Biotectra until 1999) started its operation in January 1996. As the first task Unitectra took over the compilation of the biotech company directory, which was published in May 1996. The di- rectory listed more than 170 companies with various activities in biotechnology and for the first time provided a comprehensive overview of the Swiss biotech landscape. ${ }^{[1,2]}$ This analysis and later, updated editions of the directory, changed the perception of Swiss biotechnology both in Switzerland and abroad. This was accompanied by an increasing number of biotech start-up companies, many of them established as spin-offs from universities or from the Federal Institutes of Technology in Lausanne and Zurich. Within a few years these developments promoted Switzerland to one of the leading biotech nations in Europe; a position it has maintained since then. ${ }^{[3-7]}$ This is particularly true for the creation of new biomedical start-ups as shown in a recent study. ${ }^{[8]}$

\section{Establishing the Swiss Biotech Association}

With the directory of Swiss biotech companies at hand and in view of the forthcoming national referendum on a constitutional prohibition of genetic engineering in June 1998, Ghisalba together with Unitectra decided to facilitate the creation of a national biotech trade association. The main focus was to provide a voice to small- and medium-sized enterprises (SME) that so far had been forgotten in the public debate due to their lack of resources. After presenting the concept to a small group of handpicked SME entrepreneurs, the idea quickly gained momentum and in March 1998 the SBA, initially called Vereinigung der Schweizerischen Biotechnologie-Unternehmen (VSBU), was founded in the capital city of Bern, comprising 53 founding member companies.

The SBA played an important role in the last phase of the political campaign leading up to the vote in June of the same year in which Swiss citizens voted in favor of genetic engineering. The vote gained major international attention particularly in Europe, where modern biotechnology at that time was met with widespread skepticism. Since its foundation, the SBA has continuously grown and has developed into a recognized association with more 
than 250 member companies that broadly represent the interests of the Swiss biotech industry, both within Switzerland and abroad (www.swissbiotech.org).

\section{From Lab Bench to Market - The Technology Transfer Organization Unitectra}

Building a bridge between academic research and industry was one of Ghisalba's and the SPP BioTech's major goals. The projects funded were strongly encouraged to engage in industry collaborations. In order to assist researchers in their endeavors, Ghisalba and Max Burger, President of SPP BioTech, decided to establish a technology transfer office (TTO). The organization was called Unitectra and initially consisted of two persons, Herbert Reutimann and Adrian Sigrist. Both of them had worked in the pharmaceutical industry prior to joining the TTO. Unitectra's mandate consisted of building up a range of services to support the researchers assisting them in the commercialization of research results and to facilitate joint research projects with companies.

The establishment of a TTO within the SPP BioTech that provides professional assistance to researchers in the commercialization of their research results was a visionary decision by Ghisalba. Few researchers at that time made efforts to actively transfer their research into practical applications and most scientists had neither the necessary know-how about legal nor IP aspects. As a result, the potential of academic research to foster innovation was not fully exploited. Ghisalba realized that Swiss universities could do better

The establishment of professional technology transfer services at universities in the US were boosted by new legislation in 1980 known as the Bayh-Dole Act. ${ }^{[9-11]}$ In the early nineties only very few European universities had an established TTO. In Switzerland the two Federal Institutes of Technology created offices in the early nineties that initially provided mainly administrative support. None of the cantonal universities offered any assistance to their researchers in this field. Unitectra's idea was to establish a sustainable operation that would strive to gain universities as partners in parallel to their work with SPP BioTech. They therefore would be able to develop technology transfer beyond the SPP BioTech, which was welcomed and supported by Ghisalba and the Swiss National Science Foundation from the outset. Thanks to this approach Unitectra played an important role in professionalizing technology transfer at various Swiss universities and in establishing meaningful and lean policies and processes. Besides the work for the SPP BioTech (1996-2001) and its shareholders, the University of Zurich (since 1996), the University of Bern (since 1999) and the University of Basel (since 2011), Unitectra has over the years also supported technology transfer activities at other universities (Fribourg, Geneva), universities of applied sciences (Bern, Zurich), and other public research institutions and hospitals. Together with the TTOs of the University of Geneva, EPFL and ETHZ it also played a key role in establishing swiTT, the Swiss Technology Transfer Association, which was founded in 2003 and has since then played an active role in further optimizing the interface between industry and academia.

The core responsibilities of Unitectra comprise the following tasks that are all performed in close collaboration between the researchers and the technology transfer specialists:

1) Evaluation: The commercial potential of research results and the most promising route for their transfer into practical application is evaluated and often includes seeking early feedback from potential industry partners.

2) IP protection: In many business sectors solid IP protection is a key company requirement before investing into an often lengthy and expensive product development project. In most cases this happens through the filing of patent applications, since the majority of Unitectra's business is dealing with inventions in biomedical or medical devices areas. In these sec- tors patents are crucial in view of the high investments required for developing new products and getting them approved by the regulatory authorities. Other means of protection commonly applied include the filing of trademarks or copyright. One of the challenges in protecting academic IP concerns timing. Academics are under great pressure to continuously publish their results. This might lead to situations where a patent application must be filed at a premature stage in order to avoid disclosure. Delaying scientific publications just for IP reasons is usually not acceptable in the academic environment. Unitectra annually files priority patent applications for 70 to 100 inventions. Licenses are granted whenever possible within 30 months after filing, i.e. prior to the nationalization of the patent application. So, to maintain IP protection costs at a reasonable level, the patent application portfolio is actively managed by Unitectra. Applications might be dropped for various reasons, e.g. because the technology did not meet the expectations or previously unknown prior art surfaced. Carrying patent applications at universities' own costs into the national phase is done only very selectively for inventions with significant business potential.

3) Search for business partners: Research results generated in academia in most cases are at a very early stage. Thus, their commercialization most often requires significant development efforts by a business partner. Researchers' contacts are often great leads to identify potentially interested companies. This is complemented with the broad network of the TTO and various other sources. The gap between what universities can offer and the expectations and requirements of a business partner represents a major bottleneck in the whole process. Companies usually prefer to invest in mature projects in order to reduce the risk associated with the often large investment required to develop the technology and to bring related products to the market. Thus, companies often demand data and information which go beyond a typical academic research project. To account for the situation, the Universities of Basel, Bern and Zurich each have their own translational research initiatives to close this gap, such as the Wyss Translational Center in Zurich, SITEM Insel in Bern or the DBE Department in Allschwil/Basel.

4) Licensing: Intellectual property that is developed at the universities is licensed to companies that are both interested and able to develop the technology and to commercialize products based thereon. The licensee is obliged to undertake the development and commercialization of the licensed technology, i.e. a company cannot use the license to just block third parties' access to the technology. Licenses are granted for various intellectual property developed at the universities, such as patent rights, unpatented biological material, software or other copyright-protected items, trademarks, and know-how. The scope of any license is specific for any given technology and needs to be tailored to the specific situation with regard to exclusivity, field of use, geographical scope, financial terms, diligence obligations, etc. Since university technologies are often at an early stage, as mentioned above, established companies tend to shy away from the high risk involved in developing the technology. This is particularly true for the biomedical sector where potential industry partners usually expect a comprehensive data package about the mode of action, data from various relevant animal models and preferably initial human data. The compilation of such complete data sets is often a challenge for academic research groups. In such cases, spin-off companies play an important role in developing the technology, provided financial investors are willing to fund the new venture. Once project development has reached sufficient maturity, typically comprising initial clinical trials, the technology frequently is 
sublicensed to a big pharma company for final development. Such a large partner also has the necessary resources to carry the product through regulatory approval and to bring it to the market. Alternatively, the spin-off company might be acquired completely by big pharma. Thus, licensing to spin-off companies is a common route for the commercialization of academic research results. Spin-off licenses typically are structured differently in comparison to licenses to established companies. Equity provisions instead of cash payments (usually due upon signing the license agreement and upon reaching early development milestones) avoid a cash drain on the young companies. In most cases such equity provisions are also favored by investors.

5) Spin-off companies: At the start of Unitectra in the mid-nineties, the creation of spin-off companies on the basis of research results from university was still a very rare phenomenon. In the past two decades this has changed significantly. Nowadays, spin-offs represent an important and quite common instrument in technology transfer. More than 200 spin-offs were established from the three universities in this time period. Not included in this figure are other start-up companies that were created by university graduates, but that are not based on a university license. There are different components that led to this very positive development in new venture creations besides the support of TTO's, such as (a) increased efforts in entrepreneurial education, (b) the improved situation in regard to the financing of new ventures through the development of business angel communities, family offices and venture capital firms, (c) a growing community of entrepreneurs willing to share their experience, and (d) a wide selection of other supporting organizations, both public and private initiatives, which provide assistance in the establishment and development of new companies. In addition, successful spin-offs and start-ups and the people behind them nowadays are recognized both through numerous awards and the media. Such local role models are powerful motivators for other people to set-up their own business.

With his visionary, long-term thinking and his strong dedication to the implementation of specific policies, measures and activities, Oreste Ghisalba played, over many years, a vital role in developing the biotechnology sector in Switzerland and in increasing its competitiveness on an international scale. Moreover, with the foundation of Unitectra and its continuous support for more than 20 years as a member of the Board of Directors, he has been an important driver in strengthening innovation in Switzerland. Unitectra and its shareholders, the Universities of Basel, Bern and Zurich, are deeply indebted to Oreste Ghisalba for his outstanding contribution.

\section{0 years of Unitectra (1999-2019) - some key figures}

\section{A) Commercialization of Research Results}

2,000 invention disclosures evaluated

1,200 priority patent applications filed

1,000 license agreements signed

$200+$ spin-off companies from universities supported

110 products on the market (not including licensed research reagents)

30 new chemical entities (NCE) in clinical development

\section{B) Research Collaborations}

16,000 agreements for collaborative research projects signed CHF 1.6 billion in cash contributions received by universities from these projects

[1] O. Ghisalba, H. Reutimann, A. Sigrist, Die Volkswirtschaft - Magazin für WirtschaftsPolitik 1996, 11, 12

[2] A. Sigrist, in 'Biotechnologie-Firmenkompendium für die Schweiz', Eds. Programmleitung des SPP BioTech und Biotectra, 1996.

[3] H. Reutimann, O. Ghisalba, A. Sigrist, Business Guide to Switzerland 1998, 3, 4.

[4] H. Reutimann, F. Bieri, J. Comm. Biotechnol. 2000, 6, 199.

[5] O. Ghisalba, H. Reutimann, Chimia 2000, 54, 141.

[6] F. Bieri, O. Ghisalba, O. Käppeli, H. Reutimann, in 'Encyclopedia of Ethical, Legal and Policy Issues in Biotechnology', Eds. T. J. Murray, M. J. Mehlman, John Wiley \& Sons, 2000, pp 739.

[7] Swiss Biotech Report, 2019

[8] B. van Wilgenburg, K. can Wilgenburg, K. Paisner, S. van Deventer, R.W. Rooswinkel, Nat. Biotechnol. 2019, 37, 345.

[9] 'Technology Transfer - Administration of the Bayh-Dole Act by Research Universities', United States General Accounting Office (GAO), Report to Congressional Committees, May 7, 1998.

[10] '35 U.S. Code Chapter 18 - Patent Rights in Inventions made with Federal Assistance', 1980, amended 2000.

[11] Electronic Code of Federal Regulations (e-CFR), Title 37: 'Patents, Trademarks and Copyright, Chapter IV: National Institute of Standards and Technology, Department of Commerce, Part 401: Rights to Inventions made by Nonprofit Organizations and Small Business Firms under Government Grants, Contracts, and Cooperative Agreements', 1987.

\section{License and Terms}

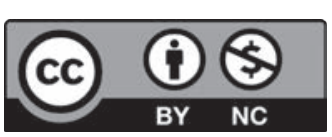

This is an Open Access article under the terms of the Creative Commons Attribution License CC BY_NC 4.0. The material may not be used for commercial purposes.

The license is subject to the CHIMIA terms and conditions: (http:// chimia.ch/component/sppagebuilder/?view=page\&id=12).

The definitive version of this article is the electronic one that can be found at doi:10.2533/chimia.2020.360 